\title{
Clinically Applicable Cyclotron-Produced Gallium-68 Gives High-Yield Radiolabeling of DOTA-Based Tracers
}

\author{
Emma Jussing ${ }^{1,2, *,+}$, Stefan Milton ${ }^{1,2, \dagger}$, Erik Samén ${ }^{1,2}$, Mohammad Mahdi Moein ${ }^{1,2}$, Lovisa Bylund ${ }^{2}$, \\ Rimma Axelsson ${ }^{3,4}$, Jonathan Siikanen ${ }^{1,3}$ and Thuy A. Tran 1,2,* \\ 1 Department of Oncology and Pathology, Karolinska Instituted, SE-171 77 Stockholm, Sweden; \\ stefan.milton@sll.se (S.M.); erik.samen@ki.se (E.S.); mohammad.moein@sll.se (M.M.M.); \\ jonathan.siikanen@ki.se (J.S.) \\ 2 Department of Radiopharmacy, Karolinska University Hospital, SE-171 76 Stockholm, Sweden; \\ Lovisa.bylund@sll.se \\ 3 Department of Medical Radiation Physics and Nuclear Medicine, Karolinska University Hospital, \\ SE-171 76 Stockholm, Sweden; Rimma.Axelsson@ki.se \\ 4 Department of Clinical Science, Intervention and Technology, Karolinska Instituted, \\ SE-171 77 Stockholm, Sweden \\ * Correspondence: emma.jussing@ki.se (E.J.); thuy.tran@ki.se (T.A.T.); Tel.: +46-72-599-10-00 (E.J.); \\ +46-72-741-89-88 (T.A.T.) \\ + Equally contributed.
}

\section{check for} updates

Citation: Jussing, E.; Milton, S.; Samén, E.; Moein, M.M.; Bylund, L.; Axelsson, R.; Siikanen, J.; Tran, T.A. Clinically Applicable

Cyclotron-Produced Gallium-68 Gives High-Yield Radiolabeling of DOTA-Based Tracers. Biomolecules 2021, 11, 1118. https://doi.org/ 10.3390/biom 11081118

Academic Editor: Jeroen A. C. M. Goos

Received: 30 June 2021

Accepted: 20 July 2021

Published: 29 July 2021

Publisher's Note: MDPI stays neutral with regard to jurisdictional claims in published maps and institutional affiliations.

Copyright: (c) 2021 by the authors. Licensee MDPI, Basel, Switzerland. This article is an open access article distributed under the terms and conditions of the Creative Commons Attribution (CC BY) license (https:// creativecommons.org/licenses/by/ $4.0 /)$.
Abstract: By using solid targets in medical cyclotrons, it is possible to produce large amounts of ${ }^{68} \mathrm{GaCl}_{3}$. Purification of $\mathrm{Ga}^{3+}$ from metal ion impurities is a critical step, as these metals compete with $\mathrm{Ga}^{3+}$ in the complexation with different chelators, which negatively affects the radiolabeling yields. In this work, we significantly lowered the level of iron ( $\mathrm{Fe}$ ) impurities by adding ascorbate in the purification, and the resulting ${ }^{68} \mathrm{GaCl}_{3}$ could be utilized for high-yield radiolabeling of clinically relevant DOTA-based tracers. ${ }^{68} \mathrm{GaCl}_{3}$ was cyclotron-produced and purified with ascorbate added in the wash solutions through the UTEVA resins. The ${ }^{68} \mathrm{Ga}$ eluate was analyzed for radionuclidic purity (RNP) by gamma spectroscopy, metal content by ICP-MS, and by titrations with the chelators DOTA, NOTA, and HBED. The ${ }^{68} \mathrm{GaCl}_{3}$ eluate was utilized for GMP-radiolabeling of the DOTA-based tracers DOTATOC and FAPI-46 using an automated synthesis module. DOTA chelator titrations gave an apparent molar activity (AMA) of $491 \pm 204 \mathrm{GBq} / \mu \mathrm{mol}$. GMP-compliant syntheses yielded up to $7 \mathrm{GBq} /$ batch $\left[{ }^{68} \mathrm{Ga}\right.$ ]Ga-DOTATOC and $\left[{ }^{68} \mathrm{Ga}\right] \mathrm{Ga}-F A P I-46$ (radiochemical yield, RCY $\sim 60 \%$, corresponding to ten times higher compared to generator-based productions). Full quality control (QC) of ${ }^{68} \mathrm{Ga}$-labelled tracers showed radiochemically pure and stable products at least four hours from end-of-synthesis.

Keywords: cyclotron-produced gallium-68; ascorbate; DOTATOC; FAPI-46; DOTA chelator

\section{Introduction}

Gallium-68 $\left({ }^{68} \mathrm{Ga}\right)$ is a positron-emitting radioisotope with a half-life of $68 \mathrm{~min}$. This relatively short half-life is suitable for positron emission tomography (PET) diagnostics when radiolabeling small molecules with fast pharmacokinetics [1,2].

The ${ }^{68} \mathrm{Ge} /{ }^{68} \mathrm{Ga}$-generators are easy to use but do suffer from several drawbacks. The small amount of radioactivity that can be eluted (e.g., $1.5 \mathrm{GBq}$ from a new generator) requires multiple generators to scale up radiopharmaceutical production. After elution, several hours are needed for ${ }^{68} \mathrm{Ga}$ ingrowth before satisfactory radioactivity levels can be eluted again. This means the generator may be used for radiolabeling 2-3 times a day during normal working hours. Additionally, decay of the parent ${ }^{68} \mathrm{Ge}$ leads to elution of less and less ${ }^{68} \mathrm{Ga}$ radioactivity over the generator lifespan. If $3-4$ patient doses per batch are typically obtained when the generator is new, only 1-2 doses per batch are produced toward the end of its use. The worldwide demand for ${ }^{68} \mathrm{Ga}$-based radiopharmaceuticals 
is constantly increasing, particularly since the successful introduction of theranostics, in which ${ }^{68} \mathrm{Ga}$ is the diagnostic radionuclide. Although the commercial production of generators has recently expanded, there is still an unmet need for ${ }^{68} \mathrm{Ga}$, with long delivery times and relatively high pricing. Another drawback is the need to store expired generators for several years before destruction due to the 271-day half-life of germanium-68 $\left({ }^{68} \mathrm{Ge}\right)$.

The approval of ${ }^{68} \mathrm{Ge} /{ }^{68} \mathrm{Ga}$-generators has tremendously facilitated the clinical implementation of several ${ }^{68} \mathrm{Ga}$-labelled tracers in the last five years. The availability of ${ }^{68} \mathrm{Ge} /{ }^{68} \mathrm{Ga}$-generators has had undoubted importance for the development of new radiopharmaceuticals for preclinical applications to clinical implementation, as well as for enabling hospitals without access to a cyclotron to produce their own PET radiopharmaceuticals [2,3].

Altogether, these limiting factors have driven the development of alternatives to ${ }^{68} \mathrm{Ge} /{ }^{68} \mathrm{Ga}$-generators to improve the availability of ${ }^{68} \mathrm{Ga}$ [4]. The ability to produce ${ }^{68} \mathrm{Ga}$ with a low-energy cyclotron is an important development and has recently been clinically implemented [5].

The cyclotron production of ${ }^{68} \mathrm{Ga}$ is feasible using either liquid or solid targets. In liquid-target productions, a solution of enriched ${ }^{68} \mathrm{Zn}$ salt is irradiated to produce the desired radiometal via the ${ }^{68} \mathrm{Zn}(\mathrm{p}, \mathrm{n}){ }^{68} \mathrm{Ga}$ reaction $[6,7]$. The zinc solution to be irradiated is conveniently transferred through transfer lines to the target holder before irradiation and also after irradiation to the synthesis hot cell for purification and radiolabeling in the radiopharmaceutical production. The yields of radiopharmaceuticals produced from liquid target ${ }^{68} \mathrm{Ga}$ are similar or slightly increased compared to those using a ${ }^{68} \mathrm{Ge} /{ }^{68} \mathrm{Ga}$-generator.

Production of ${ }^{68} \mathrm{Ga}$ by the ${ }^{68} \mathrm{Zn}(\mathrm{p}, \mathrm{n})^{68} \mathrm{Ga}$ reaction using solid-target systems on lowenergy medical cyclotrons [8-10] has yielded the highest radioactivity, up to $370 \mathrm{GBq}$ [11]. In both liquid- and solid-target productions, it is of critical importance to separate ${ }^{68} \mathrm{Ga}$ from the irradiated ${ }^{68} \mathrm{Zn}$ and other metal ions. Many separation techniques have been suggested [12]. Incompletely removed metal ion impurities compete with $\mathrm{Ga}^{3+}$ in the complexation with different chelators, which negatively affects the radiolabeling yields. In addition to the zinc that must be removed, predominantly, the metal ion of concern is the trivalent $\mathrm{Fe}^{3+}[13]$, which has a higher stability constant $\left(\log \mathrm{K}_{\mathrm{ML}}\right)$ for the chelator 1,4,7,10-tetraazacyclododecane-1,4,7,10-acetic acid (DOTA), for example, than $\mathrm{Ga}^{3+}[14,15]$.

Our group has recently developed a solid-target ${ }^{68} \mathrm{Ga}$ production purification sequence based on double anion exchange Uranium and TEtraValents Actinides $\left(\right.$ UTEVA $\left.^{\circledR}\right)$ resin columns, washed in an effective last step with hydrochloric acid $(\mathrm{HCl})(2.5 \mathrm{~N})$ to minimize the content of $\mathrm{Zn}^{2+}$ (target material) ions remaining in the ${ }^{68} \mathrm{GaCl}_{3}$ eluate [13]. All quality requirements, according to the European Pharmacopoeia monograph for cyclotron produced ${ }^{68} \mathrm{Ga}$ [16], were fulfilled. An apparent molar activity (AMA) of $86 \pm 22 \mathrm{GBq} / \mu \mathrm{mol}$ $(n=3)$, determined by DOTA titrations, was achieved. The content of $\mathrm{Zn}$ in the eluate ( $\mathrm{Zn}$ to activity ratio) was satisfying, setting the shelf-life of the ${ }^{68} \mathrm{GaCl}_{3}$ eluate to $7.7 \mathrm{~h}$. The limiting factor was the content of $\mathrm{Fe}$ in the eluate (Fe to activity ratio), which set the final shelf-life of the ${ }^{68} \mathrm{GaCl}_{3}$ eluate to $6.4 \mathrm{~h}$. However, when using this ${ }^{68} \mathrm{GaCl}_{3}$ eluate for radiopharmaceutical productions of $\left[{ }^{68} \mathrm{Ga}\right] \mathrm{Ga}-D O T A T O C$ or $\left[{ }^{68} \mathrm{Ga}\right] \mathrm{Ga}-\mathrm{FAPI}-46$, an RCY of only approximately $25 \%$ were obtained, with a 40 or $50 \mu \mathrm{g}$ precursor, respectively. From $10 \mathrm{GBq}^{68} \mathrm{GaCl}_{3}$ eluate, $2.5 \mathrm{GBq}$ product was obtained. Although this means a three-fold higher product activity compared to generator-produced syntheses, there is still a large fraction of radioactivity that is lost during the synthesis. This prompted us to make further improvements to increase the RCY.

We hypothesized that decreasing the amount of $\mathrm{Fe}^{3+}$ in the cyclotron-produced ${ }^{68} \mathrm{GaCl}_{3}$ eluate would increase the RCY, and consequently, the AMA.

It is important to take into account that the metal ions are in constant equilibrium with the surrounding negatively charged counter ions and water molecules that act as ligands and form metal complexes. The speciation of the metal complexes is of crucial importance due to the charge and electrostatic interactions with the surrounding environment. High concentrations of chloride, and low $\mathrm{pH}$, favor the formation of negatively charged complexes, such as $\left[\mathrm{FeCl}_{4}\right]^{-}$and $\left[\mathrm{GaCl}_{4}\right]^{-}$. The negatively charged complexes 
follow the $\mathrm{HCl}$ concentration and the distribution coefficients of the metal ions for the UTEVA resin [17-19]. The active part of the UTEVA resin consists of a neutral dipentyl pentylphosphonate complexing ligand for the metal ion [17]. The reduction potential of $\mathrm{Fe}^{3+}$ to $\mathrm{Fe}^{2+}$ at a low $\mathrm{pH}$ is around $+0.8 \mathrm{~V}$ and of $\mathrm{Ga}^{3+}$ to $\mathrm{Ga}^{2+}$ at around $-0.6 \mathrm{~V}[20,21]$. The oxidation potential of ascorbic acid at low $\mathrm{pH}$ is around $-0.3 \mathrm{~V}$ [22]. Due to the lower reduction potential of $\mathrm{Ga}^{3+}$, which is lower than the oxidation potential of ascorbic acid, the result is a reduction of $\mathrm{Fe}^{3+}$ to $\mathrm{Fe}^{2+}$, while gallium is kept in the form of $\mathrm{Ga}^{3+}$. See Figure 1 below.

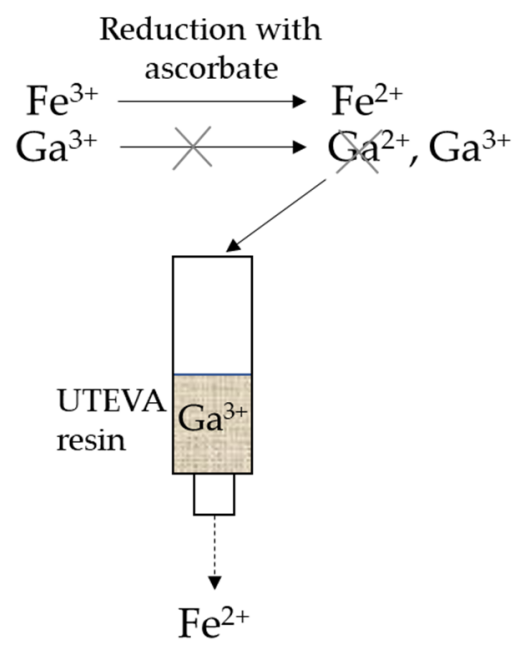

Figure 1. $\mathrm{Fe}^{3+}$ is reduced to $\mathrm{Fe}^{2+}$ by sodium ascorbate, decreasing the stability constant $\left(\log \mathrm{K}_{\mathrm{ML}}\right)$ to the UTEVA resin. $\mathrm{Ga}^{3+}$ is not reduced by sodium ascorbate.

The aim of this work was to improve the purification methodology of the solid target production of ${ }^{68} \mathrm{Ga}$. By adding ascorbate to the purification steps, the level of $\mathrm{Fe}^{3+}$ in the ${ }^{68} \mathrm{GaCl}_{3}$ eluate was significantly decreased; thus, enabling high-yield radiolabeling of clinically relevant DOTA-based tracers, such as DOTATOC and FAPI-46.

\section{Materials and Methods}

\section{1. ${ }^{68} \mathrm{Ga}$ Production and Purification Modification with Added Ascorbate}

${ }^{68} \mathrm{GaCl}_{3}$ was produced via the ${ }^{68} \mathrm{Zn}(\mathrm{p}, \mathrm{n}){ }^{68} \mathrm{Ga}$ and purified according to our previous method [13], except with an addition of $500 \mathrm{mg}$ of sodium ascorbate (Apotekets Produktion och Laboratorier (APL), Stockholm, Sweden), divided between the $\mathrm{HCl}$ dilution and wash solutions as shown in Figure 2. In short, $110 \mathrm{mg}{ }^{68} \mathrm{Zn}$ enriched ( $\left.98.7 \pm 0.2 \%\right)$ foil (Isoflex, San Francisco, CA, USA) was pneumatically transferred using a transfer module (Comecer EDS) to the cyclotron's irradiation station (GE Healthcare, Uppsala, Sweden, PETtrace 800 and Comecer PTS). Irradiation was performed with a proton beam current of $25 \mu \mathrm{A}$ for $68 \mathrm{~min}$. Dissolution and separation were fully automated using a cassettebased Taddeo PRF module (Comecer, Castel Bolognese, Italy), and all materials and acids used were of metal-free quality, as stated in [13]. The RNP of the eluate was determined by gamma spectroscopy using a high-purity germanium detector (Canberra with CryoCycle II Hybrid Cryostat), radionuclidic identity was determined by half-life measurement using a dose calibrator (Capintec CRC-55tR, LabLogic, Sheffield, United Kingdom), as described in [13]. 


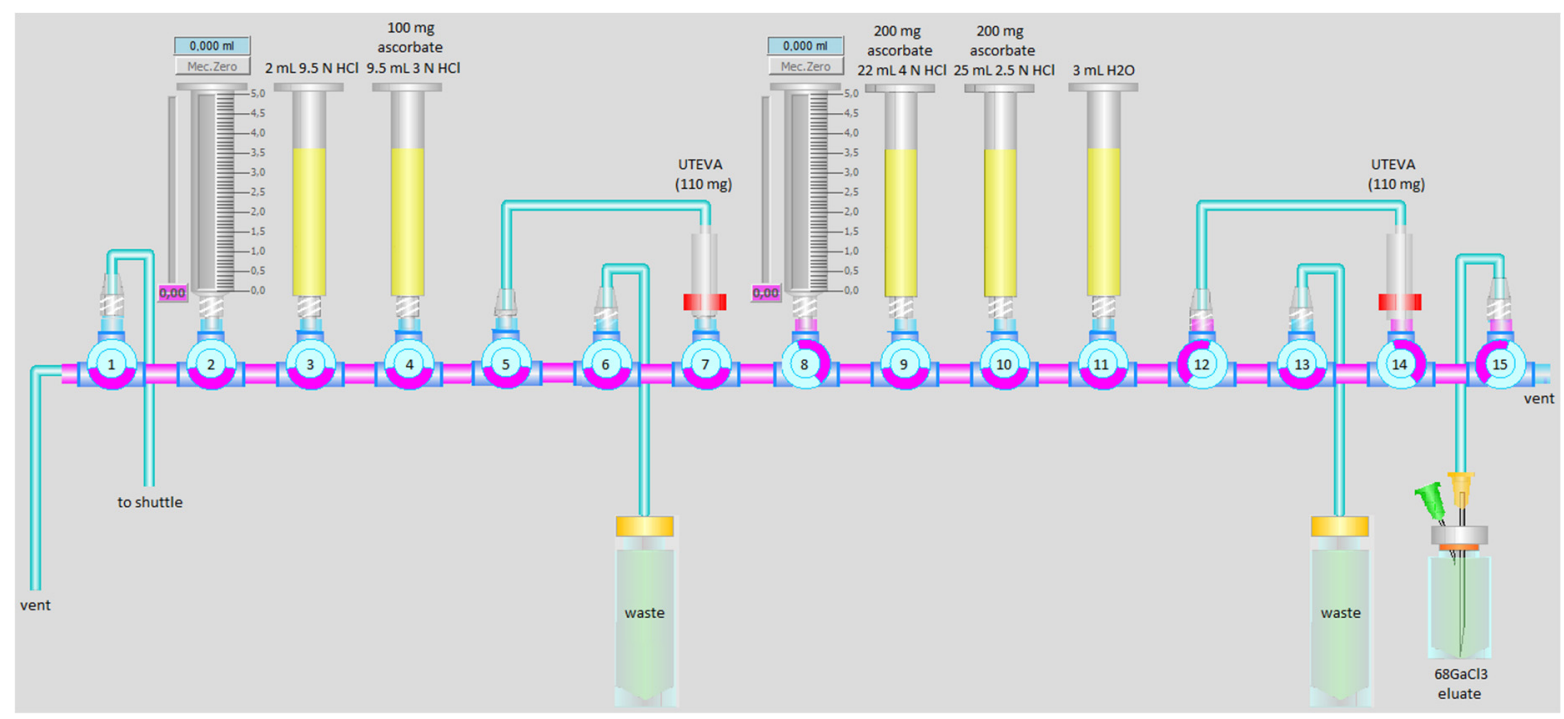

Figure 2. Schematic illustration of the automated protocol used for the separation of ${ }^{68} \mathrm{Ga}$ from enriched ${ }^{68} \mathrm{Zn}$, using a cassette-based Taddeo PRF module (Comecer). To decrease the $\mathrm{Fe}^{3+}$ impurity, sodium ascorbate was added in position 4 (100 mg), position 9 (200 mg), and position 10 (200 mg).

\subsection{Colorimetric Test of Iron Content and ICP-MS Measurements}

To investigate that iron was eliminated to a larger extent when reduced to $\mathrm{Fe}^{2+}$ using ascorbate in the UTEVA resin purification method, we first performed a cold colorimetric measurement of the content of iron present in the rinses with or without the addition of ascorbate. The UTEVA resin $(110 \mathrm{mg})$ was loaded with $\mathrm{Fe}^{3+}\left(\mathrm{Fe}(\mathrm{III}) \mathrm{Cl}_{3}\right.$, Sigma-Aldrich, Stockholm, Sweden), rinsed, and eluted in a fashion comparable to that used in the ${ }^{68} \mathrm{Ga}$ purification of this study. The UTEVA resin was conditioned with $\mathrm{HCl}(4 \mathrm{~N}, 4 \mathrm{~mL})$, $10 / 20 / 30 \mu \mathrm{g} \mathrm{Fe}^{3+}$ in $\mathrm{HCl}(4 \mathrm{~N}, 2 \mathrm{~mL}$ ) (with or without $10 \mathrm{mg} / \mathrm{mL}$ ascorbate) was loaded and trapped on the resin, following rinses with $\mathrm{HCl}(4 \mathrm{~N}, 10 \mathrm{~mL}$ ) (with or without $10 \mathrm{mg} / \mathrm{mL}$ ascorbate) and $\mathrm{HCl}(2.5 \mathrm{~N}, 8 \mathrm{~mL})$ (with or without $10 \mathrm{mg} / \mathrm{mL}$ ascorbate), and lastly dried with $20 \mathrm{~mL}$ of air. The resin was then eluted using $1 \mathrm{~mL}$ of water (TraceSelect, Honeywell, Seetze, Germany), and the eluate was collected for analysis of iron content using an iron colorimetric test (MColortest, part no. 1.14759.0001, Merck, Darmstadt, Germany). The $p$-values were calculated using the Student's $t$-test in Excel (Microsoft ${ }^{\circledR}$ Excel ${ }^{\circledR}$ for Microsoft 365MSO); $p<0.05$ was considered statistically significant.

${ }^{68} \mathrm{GaCl}_{3}$ eluate from one ${ }^{68} \mathrm{Ga}$ solid-target cyclotron production with added ascorbate, and one without ascorbate, were analyzed by Inductively Coupled Plasma-Mass Spectrometry (ICP-MS) externally (ALS, Umeå, Sweden). The analysis included the following metal ions, $\mathrm{Zn}$ (calibrated for ${ }^{68} \mathrm{Zn}$ instead of natZn), $\mathrm{Fe}, \mathrm{Ga}, \mathrm{Al}, \mathrm{Cd}, \mathrm{Cu}, \mathrm{Ge}, \mathrm{Mo}, \mathrm{Ni}, \mathrm{Pb}, \mathrm{Pt}$, and Ti.

\subsection{Chelator Titrations and AMA Determination}

AMA of the cyclotron-produced ${ }^{68} \mathrm{GaCl}_{3}$ eluate was determined on $50 \mu \mathrm{L}$ ( $5 \%$ of total eluate volume) by titration with the chelators DOTA (Sigma-Aldrich), (1,4,7triazonane-1,4,7-triyl) triacetic acid (NOTA) (CheMatech, Dijon, France), and N,N'-Di(2hydroxybenzyl)ethylenediamine- $N, N^{\prime}$-diacetic acid monohydrochloride hydrate (HBED) (STEM Chemicals Inc., Bischheim, France). Chelator solutions were prepared in serial dilutions. Ranges of chelators labeled in the titrations, when ascorbate was used in the purification: DOTA $3.1 \mathrm{pmol}-0.1 \mathrm{nmol}$, NOTA and HBED 1.2 pmol-0.05 nmol, and when ascorbate was not used in the purification: DOTA 31.2 pmol-1.0 nmol, NOTA and HBED 15.5 pmol- $0.5 \mathrm{nmol}$. The ${ }^{68} \mathrm{GaCl}_{3}$ solution was adjusted to $\mathrm{pH} 4.0$ using sodium acetate buffer ( 1:10 acetate buffer solution pH 4.6 (Honeywell Fluka, Steinheim, Germany) in TraceSelect Water (Honeywell) $\mathrm{pH}$ adjusted with $\mathrm{HCl}$ (Honeywell)) to a final volume of 
$600 \mu \mathrm{L}$ in each vial. The vials were incubated at $95^{\circ} \mathrm{C}, 550 \mathrm{rpm}$ for $15 \mathrm{~min}$ (Eppendorf (ThermoMixer C)). The AMA was analyzed by measuring the labeling efficiency of each vial. Analysis of labeling efficiency (incorporation of ${ }^{68} \mathrm{Ga}$ in DOTA, NOTA, and HBED) was performed by radio-thin layer chromatography using iTLC-SG-strip (Agilent, Folsom, CA, USA) as stationary phase, eluted in ammonium acetate $1 \mathrm{M}$ (Sigma-Aldrich): methanol (Merck) 1:1 as mobile phase. In this analysis, free ${ }^{68} \mathrm{Ga}$ stayed at the origin (Retardation factor, Rf 0-0.1) while complexed ${ }^{68} \mathrm{Ga}$-DOTA, ${ }^{68} \mathrm{Ga}-\mathrm{NOTA}$, and ${ }^{68} \mathrm{Ga}-\mathrm{HBED}$ migrated (Rf 0.9-1.0). Radioactivity in the strips was detected by a TLC-scanner (AR-2000, Eckert \& Ziegler, Berlin, Germany), and analysis was performed using the software WinScan 3.0 (Eckert \& Ziegler). Labeling efficiency was plotted as a function of DOTA, NOTA, and HBED chelator mass $(\mu \mathrm{mol})$. AMA was calculated by the equation of the line and determined as $50 \%$ incorporation and by dividing these values by two, as suggested earlier [23]. The values were decay-corrected to the end of ${ }^{68} \mathrm{GaCl}_{3}$ eluate purification (EOP).

\subsection{Synthesis of $\left[{ }^{68} \mathrm{Ga}\right] \mathrm{Ga}$-FAPI-46 and $\left[{ }^{68} \mathrm{Ga}\right] \mathrm{Ga}$-DOTATOC}

From each cyclotron production of ${ }^{68} \mathrm{GaCl}_{3}$ (total volume of $\sim 1 \mathrm{~mL}$ ), $50 \mu \mathrm{L}$ of the eluate was used for chelator titration as described above. The remainder of the radioactivity $(\sim 11 \mathrm{GBq})$ was used for each radiopharmaceutical synthesis.

Automated radiosynthesis was performed on an Eckert \& Ziegler Modular-Lab PharmTracer synthesis module using the Modular-Lab software (Eckert \& Ziegler). See Figure 3 for a schematic flow diagram of the synthesis. All materials used for radiolabeling were of GMP grade and metal-free quality if not otherwise stated. All buffer kits and hardware kits (synthesis cassettes) for the syntheses were purchased from Eckert \& Ziegler.

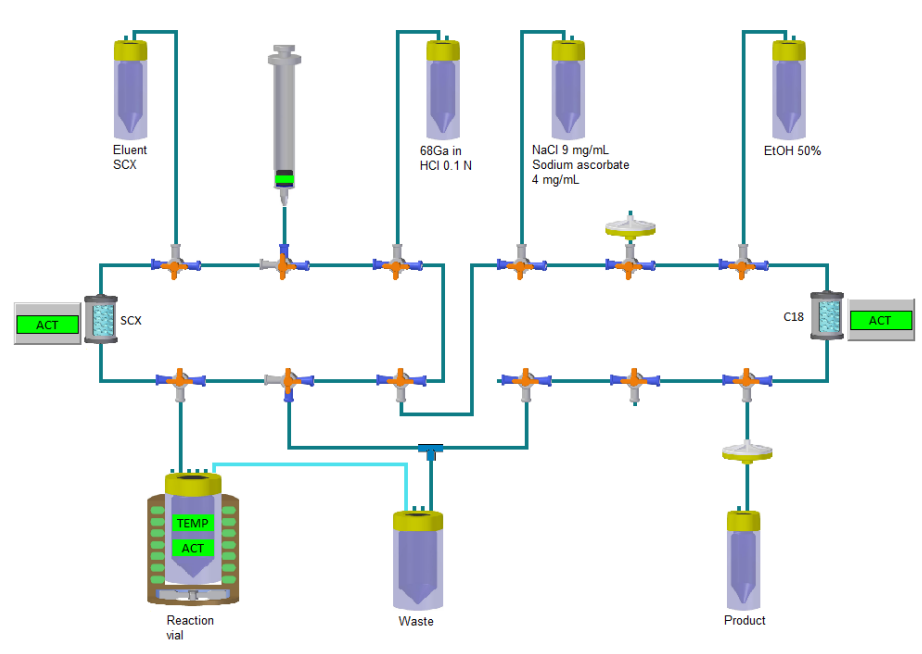

(a)

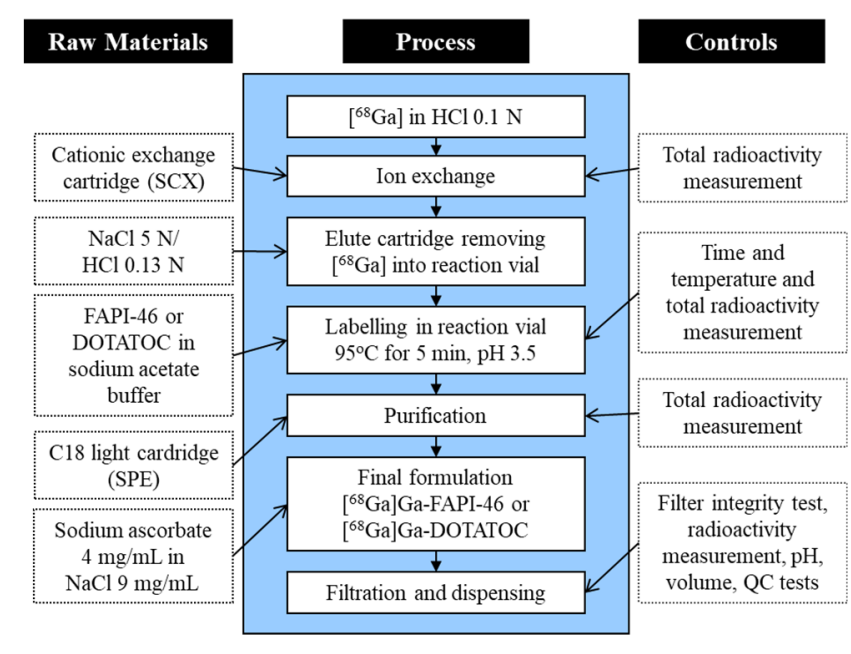

(b)

Figure 3. (a) Schematic illustration for the synthesis of $\left[{ }^{68} \mathrm{Ga}\right] \mathrm{Ga}-F A P I-46$ or $\left[{ }^{68} \mathrm{Ga}\right] \mathrm{Ga}-\mathrm{DOTATOC}$ using Modular-Lab Pharmtracer (Eckert and Ziegler). (b) Flow diagram of the GMP-compliant synthesis of ${ }^{68}$ Ga-based radiopharmaceuticals using Modular-Lab Pharmtracer synthesis module.

The ${ }^{68} \mathrm{GaCl}_{3}$ eluate was diluted to $4-5 \mathrm{~mL}$ with $0.1 \mathrm{~N} \mathrm{HCl}$ (Eckert \& Ziegler) to minimize activity losses in the synthesis cassette-connected eluate transfer tube. The reaction vessel was prepared to contain $50 \mu \mathrm{g}$ of FAPI-46 precursor (Sofie Biosciences, Totowa, NJ, USA) or $40 \mu \mathrm{g}$ of DOTATOC precursor (ABX, advanced biochemical compounds, Radeberg, Germany) and buffer solution ( $54 \mathrm{mg}$ sodium acetate trihydrate, $18 \mu \mathrm{L}$ $30 \% \mathrm{HCl}, 8 \mu \mathrm{L}$ glacial acetic acid, $2.4 \mathrm{~mL}$ TraceSelect water, and $0.2 \mathrm{~mL}$ ethanol). The diluted ${ }^{68} \mathrm{GaCl}_{3}$ eluate was transferred to the synthesis unit and trapped on a cationic exchange cartridge (SCX in the synthesis scheme, Figure 3a) and eluted into the reaction vial with $0.7 \mathrm{~mL}$ of sodium chloride $(\mathrm{NaCl}) 5 \mathrm{~N} / \mathrm{HCl} 0.13 \mathrm{~N}$. The final volume of the reaction mixture was $3.3 \mathrm{~mL}, \mathrm{pH}$ 3.5. The labeling reaction mixture was heated to $95{ }^{\circ} \mathrm{C}$ for $5 \mathrm{~min}$. After 
the end of the labeling, the crude product was diluted with $2 \mathrm{~mL}$ of $4 \mathrm{mg} / \mathrm{mL}$ sodium ascorbate in $9 \mathrm{mg} / \mathrm{mL} \mathrm{NaCl}$ and trapped on a reversed-phase solid-phase extraction (SPE) cartridge (C18 in the synthesis scheme, Figure 3a). The SPE was rinsed to waste using $4 \mathrm{~mL}$ of $4 \mathrm{mg} / \mathrm{mL}$ sodium ascorbate in $9 \mathrm{mg} / \mathrm{mL} \mathrm{NaCl}$ to remove any remaining free ${ }^{68} \mathrm{Ga}$ ions in the system. The trapped product was then eluted from the SPE, using $1.2 \mathrm{~mL}$ of ethanol/water 1:1, through a $0.22 \mu \mathrm{m}$ sterile filter (Millex-GV, Merck Millipore, Darmstadt, Germany) into the product vial. The product ([ $\left.{ }^{68} \mathrm{Ga}\right] \mathrm{Ga}-\mathrm{FAPI}-46$ or $\left.\left[{ }^{68} \mathrm{Ga}\right] \mathrm{Ga}-\mathrm{DOTATOC}\right)$ was lastly diluted with $4 \mathrm{mg} / \mathrm{mL}$ sodium ascorbate (APL, Sweden), as a radiolytic stabilizer, in $9 \mathrm{mg} / \mathrm{mL} \mathrm{NaCl}$ to a final formulation volume of approximately $9.5 \mathrm{~mL}$. From the addition of eluate to the finished product, the time required was $17 \mathrm{~min}$. Radiosynthesis of these products using generator-based ${ }^{68} \mathrm{GaCl}_{3}$ eluate was performed in the same way, using eluate from a GalliaPharm generator (Eckert \& Ziegler) or a GalliAd generator (IRE ELiT, Fleurus, Belgium). The synthesis of $\left[{ }^{68} \mathrm{Ga}\right] \mathrm{Ga}-\mathrm{DOTATOC}$ was, however, performed without ascorbate as a stabilizer. A flow diagram of the syntheses is illustrated in Figure $3 \mathrm{~b}$.

\subsection{Quality Control of $\left[{ }^{68} \mathrm{Ga}\right] \mathrm{Ga}-\mathrm{FAPI}-46$ and $\left[{ }^{68} \mathrm{Ga}\right] \mathrm{Ga}-\mathrm{DOTATOC}$}

Full quality controls (QC) were performed for $\left[{ }^{68} \mathrm{Ga}\right] \mathrm{Ga}$-FAPI-46 and $\left[{ }^{68} \mathrm{Ga}\right] \mathrm{Ga}$-DOTATOC using qualified instruments if not otherwise stated. The $\mathrm{QC}$ attributes determined included the appearance by visual inspection and $\mathrm{pH}$ by $\mathrm{pH}$ strip (Merck, Darmstadt, Germany). The content of bacterial endotoxins was performed by chromogenic LAL-test method using Endosafe-Nextgen PTS (Charles River, Willmington, MA, USA), and the filter integrity was tested by a bubble point tester (DM Automation, Sweden or an in-house built, qualified bubble point tester).

The radiochemical purity (RCP), chemical purity, as well as radiochemical stability were measured by analytical radio-high performance liquid chromatography (radio-HPLC). Two different HPLC systems were used. The Agilent 1260 Infinity System is equipped with a quaternary pump, autosampler, and DAD UV detector $(254 \mathrm{~nm})$ as well as a FlowRAM 2"NaI/PMT radiodetector (LabLogic, Sheffield, United Kingdom) and the software Laura (LabLogic) was used for $\left[{ }^{68} \mathrm{Ga}\right] \mathrm{Ga}-\mathrm{FAPI}-46$. Analysis was performed on an analytical column (Agilent Poroshell 120 EC-C18, $2.7 \mu \mathrm{m} 4.6 \times 100 \mathrm{~mm}$ ) and a guard column (Poroshell 120 EC-C18 Fast guard, $3 \times 5 \mathrm{~mm}, 2.7 \mu \mathrm{m}$ ). The mobile phase was a gradient composed of $50 \mathrm{mM}$ phosphoric acid $\left(\mathrm{H}_{3} \mathrm{PO}_{4}\right)$ and acetonitrile $\left(\mathrm{CH}_{3} \mathrm{CN}\right)$; a flow rate of $0.3 \mathrm{~mL} / \mathrm{min}$ was used.

The Shimadzu HPLC system (Duisburg, Germany) is equipped with a binary pump, degasser (Biotech, Onsala, Sweden), manual injector (Rheodyne, Bensheim, Germany), and UV-VIS detector $(220 \mathrm{~nm})$, as well as a radiodetector (Bioscan, Washington, DC, USA) and the software Shimadzu LC Solution was used for $\left[{ }^{68} \mathrm{Ga}\right] \mathrm{Ga}$-DOTATOC. Analysis was performed using an analytical column (ACE 3-C18, $4.6 \times 150 \mathrm{~mm}$ ) and a guard column of the same material $(3 \mu \mathrm{m})$. The mobile phase was a gradient composed of $0.1 \%$ TFA in $\mathrm{CH}_{3} \mathrm{CN}: \mathrm{H}_{2} \mathrm{O}$, and a flow rate of $0.6 \mathrm{~mL} / \mathrm{min}$ was used.

The radiochemical impurities of ${ }^{68} \mathrm{Ga}$ ions and ${ }^{68} \mathrm{Ga}$-colloids were determined with iTLC analysis using iTLC-SG strip (Agilent). The radioactivity was detected using a radioTLC scanner, either Scan-RAM with a PS/PMT detector, equipped with the software Laura (LabLogic) or the Bioscan TLC scanner, equipped with the software Winscan (Bioscan). The mobile phase of $5 \mathrm{M}$ ammonium acetate (Merck) and methanol (Merck) in a ratio of 25:75 was used for $\left[{ }^{68} \mathrm{Ga}\right] \mathrm{Ga}-\mathrm{FAPI}-46$ while the mobile phase of $1 \mathrm{M}$ ammonium acetate (Merck) and methanol (Merck) in a ratio 1:1 was used for $\left[{ }^{68} \mathrm{Ga}\right] \mathrm{Ga}$-DOTATOC. In these systems, Rf was $\sim 0-0.2$ for ${ }^{68} \mathrm{Ga}$-impurities, and Rf was $\sim 0.6-1.0$ for ${ }^{68} \mathrm{Ga}$-labeled products.

Ethanol levels in the products were analyzed using a gas chromatograph (GC model 6850 Agilent) equipped with a flame ionization detector, an Agilent Res-Solv column $(30 \mathrm{~m} \times 0.53 \mathrm{~mm}$ ID $\times 1.0 \mu \mathrm{m}$ film), and an autoinjector. The GC method used a $2 \mu \mathrm{L}$ injection volume, a split ratio of 1:80, and helium as a carrier gas. The temperature was programmed to $35^{\circ} \mathrm{C}$ for $3.5 \mathrm{~min}$ after injection, ramped to $240{ }^{\circ} \mathrm{C}$ at a rate of $70{ }^{\circ} \mathrm{C} / \mathrm{min}$, held at $240{ }^{\circ} \mathrm{C}$ for $3 \mathrm{~min}$, and cooled to $35^{\circ} \mathrm{C}$. 
The stability (shelf-life) of ${ }^{68}$ Ga-labeled products was determined by analyzing the total radiochemical purity of the product with HPLC and iTLC as described above. Sterility tests were performed by direct inoculation by an external contractor (APL, Stockholm, Sweden).

\section{Results}

\section{1. ${ }^{68} \mathrm{Ga}$ Production and Radionuclidic Purity}

Production of ${ }^{68} \mathrm{Ga}\left(25 \mu \mathrm{A}, 68 \mathrm{~min}, 110 \mathrm{mg}{ }^{68} \mathrm{Zn}\right.$ enriched foil (Isoflex), $\left.n=8\right)$, yielded a ${ }^{68} \mathrm{GaCl}_{3}$ eluate, corrected to the end of purification, of $76 \pm 2 \%$, corresponding to $11.3 \pm 1.5 \mathrm{GBq}$. The yield was calculated as the product activity divided by the total amount of starting activity transferred to the purification cassette. The entire ${ }^{68} \mathrm{GaCl}_{3}$ eluate obtained, except for $50 \mu \mathrm{L}$ saved for titrations and other analyses, was used for individual radiolabelings (see Section 3.4). The radionuclidic purity of the eluate at the end of bombardment $(\mathrm{EOB})$ was $99.94 \pm 0.00 \%(n=4)$ and the half-life was $68.7 \pm 0.5 \mathrm{~min}(n=4)$.

\subsection{Verification of Iron Content after Addition of Ascorbate}

As illustrated in the colorimetric analysis in Figure 4, the addition of sodium ascorbate to the dilution and wash solutions significantly $(p<0.001)$ decreased the iron content compared to when no ascorbate was used. It was also evident that iron was efficiently removed by the UTEVA resin. ICP-MS analysis confirmed the efficiency of the removal of iron, as much as up to a 7-fold decrease of the iron content when sodium ascorbate was added in the purification process. ICP-MS analysis also showed that the only metal affected by the ascorbate addition was iron (see details in Table S1 in the Supplementary Materials). The affinity of $\mathrm{Fe}^{2+}$ complexes was interpreted to be lower on the UTEVA than for $\mathrm{Fe}^{3+}$ complexes, while the high affinity of $\mathrm{Ga}^{3+}$ complexes was retained.

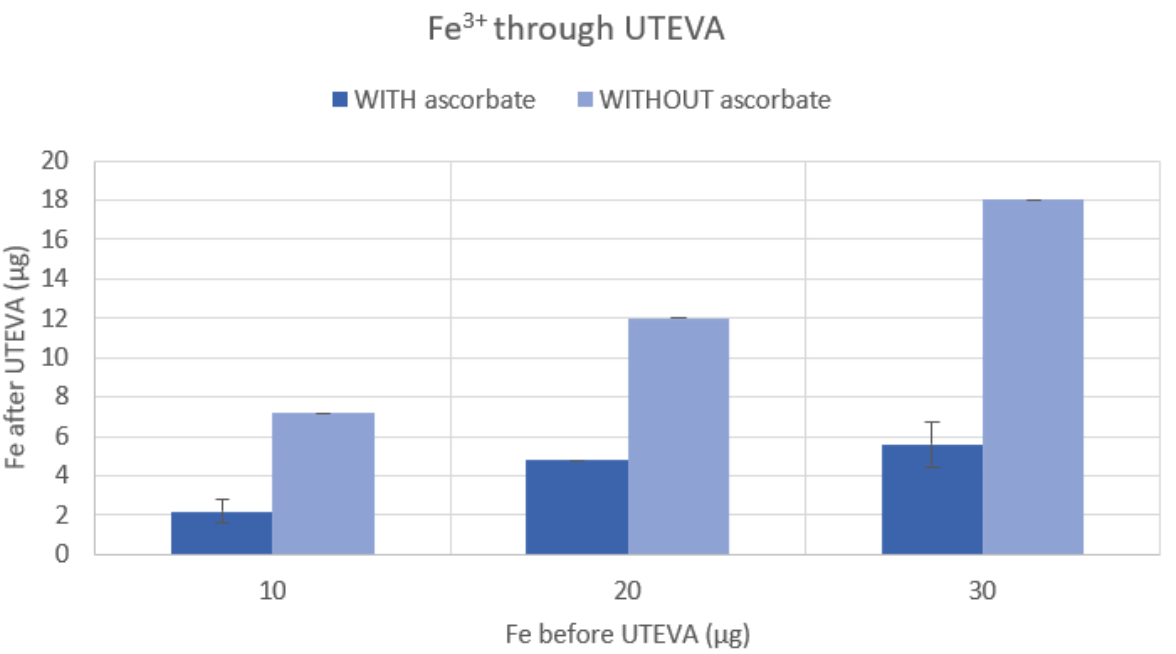

Figure 4. Comparison between the iron present in the eluate when the UTEVA resin was washed with sodium ascorbate added $\mathrm{HCl}(n=3)$ and $\mathrm{HCl}$ without sodium ascorbate $(n=3)$. The Student's $t$-test showed $p$-values $<0.001$, which were considered significant. The iron concentrations were analyzed using a colorimetric test kit.

\subsection{Titrations with DOTA, NOTA, and HBED}

AMA results for titrations with DOTA, NOTA, and HBED are summarized in Table 1 and illustrated in Figure 5. For comparison, the AMA results for titrations with DOTA using generator-produced ${ }^{68} \mathrm{Ga}$ from [13] are also shown in Table 1 . The AMA values were 2-, 3- and 16-fold higher with ascorbate for DOTA, NOTA, and HBED, respectively, verifying a considerable improvement. 
Table 1. Apparent molar activity, AMA, results from titrations with DOTA, NOTA, and HBED chelator. * For comparison, corresponding results with DOTA from the generator were taken from [13].

\begin{tabular}{cccc}
\hline & $\begin{array}{c}{ }^{68} \mathrm{GaCl}_{3} \text { from } \\
\text { Generator }\end{array}$ & \multicolumn{2}{c}{${ }^{68} \mathrm{GaCl}_{3}$ from Cyclotron } \\
\hline & $\begin{array}{c}\text { No Ascorbate } \\
(\boldsymbol{n}=\mathbf{3})\end{array}$ & $\begin{array}{c}\text { No Ascorbate } \\
(\boldsymbol{n}=\mathbf{1})\end{array}$ & $\begin{array}{c}\text { with Ascorbate } \\
(\boldsymbol{n}=\mathbf{6})\end{array}$ \\
\hline Chelator & AMA $(\mathrm{GBq} / \mu \mathrm{mol})$ & $\mathrm{AMA}(\mathrm{GBq} / \mu \mathrm{mol})$ & $\mathrm{AMA}(\mathrm{GBq} / \mu \mathrm{mol})$ \\
DOTA & $10 \pm 3$ & 209 & $491 \pm 204$ \\
NOTA & Not analyzed & 314 & $993 \pm 405$ \\
HBED & Not analyzed & 280 & $4480 \pm 3060$ \\
\hline
\end{tabular}

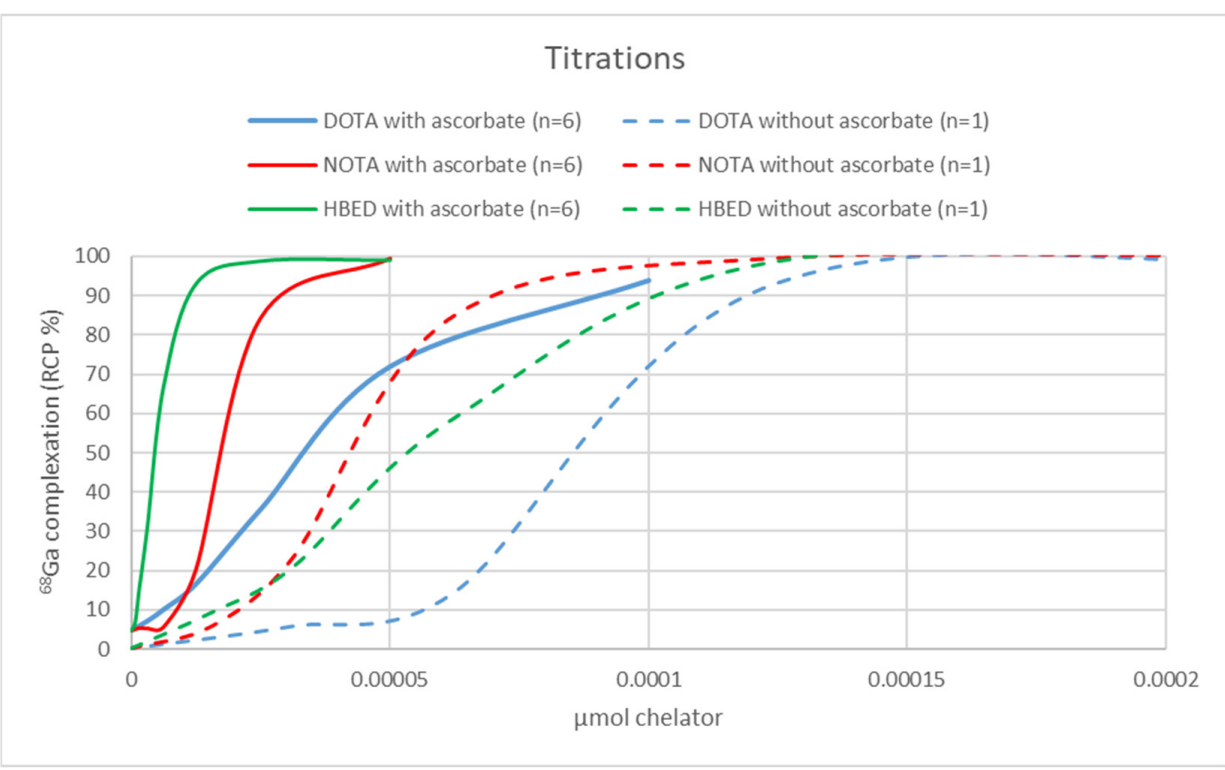

Figure 5. Comparison between DOTA, NOTA, and HBED titrations on ${ }^{68} \mathrm{GaCl}_{3}$ productions with or without sodium ascorbate addition to the dilution and wash solutions in the purification process.

\subsection{Synthesis and Quality Control of $\left[{ }^{68} \mathrm{Ga}\right] \mathrm{Ga}-\mathrm{FAPI}-46$ and $\left[{ }^{68} \mathrm{Ga}\right] \mathrm{Ga}-\mathrm{DOTATOC}$}

Summaries of the syntheses and QC of $\left[{ }^{68} \mathrm{Ga}\right] \mathrm{Ga}-F A P I-46$ and $\left[{ }^{68} \mathrm{Ga}\right] \mathrm{Ga}-D O T A T O C$ syntheses are shown in Tables 2 and 3, respectively. Data of the generator-produced syntheses of each radiopharmaceutical are based on the clinical GMP production for patients at Karolinska University Hospital. Initial test labeling of each peptide with the previous ${ }^{68} \mathrm{Ga}$ production method without ascorbate gave an RCY of less than $25 \%$ (for example, for $\left[{ }^{68} \mathrm{Ga}\right] \mathrm{Ga}-\mathrm{FAPI}-46$, the obtained batch activity was $2.45 \mathrm{GBq}$ from a starting activity of $10.8 \mathrm{GBq})$. With this new ${ }^{68} \mathrm{Ga}$ production method, including the addition of ascorbate, using the same amount of starting activity and precursor amounts, RCYs of $57 \%$ and $64 \%$ were obtained for $\left[{ }^{68} \mathrm{Ga}\right] \mathrm{Ga}-\mathrm{FAPI}-46$ and $\left[{ }^{68} \mathrm{Ga}\right] \mathrm{Ga}-\mathrm{DOTATOC}$, respectively. These RCYs were on the same level that is normally obtained with generator-produced ${ }^{68} \mathrm{Ga}$. The resulting radioactivity from each batch at EOS were $5.58 \pm 0.35 \mathrm{GBq}(n=3)$ for $\left[{ }^{68} \mathrm{Ga}\right] \mathrm{Ga}-F A P I-46$ and $6.1 \pm 1.3 \mathrm{GBq}(n=3)$ for $\left[{ }^{68} \mathrm{Ga}\right] \mathrm{Ga}$-DOTATOC. This batch radioactivity is 10 times higher than that normally obtained with generators, which were $0.58 \pm 0.09 \mathrm{GBq}(n=4)$ for FAPI-26 and $0.61 \pm 0.16 \mathrm{GBq}(n=86)$ for DOTATOC. Typical HPLC chromatograms of $\left[{ }^{68} \mathrm{Ga}\right] \mathrm{Ga}$-FAPI-46 and $\left[{ }^{68} \mathrm{Ga}\right] \mathrm{Ga}-D O T A T O C$ can be found in Figures S1 and S2, Supplementary Materials. 
Table 2. Summary of syntheses and QC of [ $\left.{ }^{68} \mathrm{Ga}\right] \mathrm{Ga}-\mathrm{FAPI}-46$.

\begin{tabular}{|c|c|c|c|}
\hline Parameter & Product Specification & $\begin{array}{l}\text { Generator-Produced } \\
\quad(n=4 \pm \text { SD })\end{array}$ & $\begin{array}{c}\text { Cyclotron-Produced } \\
(n=3 \pm \mathrm{SD})\end{array}$ \\
\hline Start activity (GBq) & Not specified & $0.99 \pm 0.16$ & $9.8 \pm 0.26$ \\
\hline Precursor mass $(\mu \mathrm{g})$ & Not specified & 50 & 50 \\
\hline Product activity / batch (GBq) & Not specified & $0.58 \pm 0.09$ & $5.58 \pm 0.35$ \\
\hline $\begin{array}{c}\text { Activity concentration } \\
(\mathrm{MBq} / \mathrm{mL})\end{array}$ & Not specified & $60.5 \pm 10.5$ & $602 \pm 45$ \\
\hline Non-decay-corrected RCY (\%) & Not specified & $58.2 \pm 3.2$ & $57.0 \pm 2.5$ \\
\hline $\operatorname{AMA}(\mathrm{GBq} / \mu \mathrm{mol})$ & Not specified & $10.0 \pm 1.7$ & $98.8 \pm 6.2$ \\
\hline Appearance & $\begin{array}{c}\text { Clear or slightly yellow. Free } \\
\text { of particles }\end{array}$ & Conforms & Conforms \\
\hline $\mathrm{pH}$ & $4.0-8.0$ & $5.3 \pm 0$ & $5.3 \pm 0.3$ \\
\hline $\begin{array}{c}\text { Product identity } \\
{\left[{ }^{68} \mathrm{Ga}\right] \text { Ga-FAPI- } 46}\end{array}$ & $\left|\mathrm{Rt}_{\mathrm{RD}}-\mathrm{Rt}_{\mathrm{UV}}\right|<60 \mathrm{~s}$ & $40 \pm 9.8$ & $31 \pm 9.5$ \\
\hline Total chemical purity $(\mu \mathrm{g} / \mathrm{mL})$ & $\leq 10 \mu \mathrm{g} / \mathrm{mL}$ & $\leq 10$ & $\leq 10$ \\
\hline Radiochemical impurity, B (\%) & $\leq 3 \%$ & $0.2 \pm 0.4$ & $0.26 \pm 0.05$ \\
\hline $\begin{array}{l}\text { Total radiochemical purity }(\%) \\
\qquad \mathrm{RCP}_{\mathrm{Tot}}=(100-\mathrm{B}) \times \mathrm{T}\end{array}$ & $\geq 91 \%$ & $98.3 \pm 0.01$ & $97.4 \pm 0.81$ \\
\hline Filter integrity (bar) & $\geq 3.5$ bar & $4.2 \pm 0.0$ * & $4.1 \pm 0.06$ \\
\hline Bacterial endotoxins $(\mathrm{EU} / \mathrm{mL})$ & $<1 \overline{7} .5 \mathrm{EU} / \mathrm{mL}$ & $<5.0$ & $<5.0$ \\
\hline Ethanol $(\%)$ & $<10 \%$ & $6.4 \pm 0.45$ & $6.8 \pm 0.26$ \\
\hline Sterility & Sterile, 0 CFU & Sterile & Sterile ${ }^{* *}$ \\
\hline Radiochemical stability $* * * *$ & $\mathrm{RCP}_{\text {Tot }} \geq 91 \%$ & $95 \pm 0.02$ & $96 \pm 1.5^{* * *}$ \\
\hline
\end{tabular}

Abbreviations: $\mathrm{RCY}=$ radiochemical yield; $\mathrm{Rt}=$ retention time; $\mathrm{RD}=$ radiodetector; $\mathrm{UV}=$ ultraviolet detector; $\mathrm{B}=$ percentage of radioactivity due to impurity $\left[{ }^{68} \mathrm{Ga}\right]$-ions or -colloids in TLC analysis; $\mathrm{T}=$ proportion of the radioactivity due to $\left[{ }^{68} \mathrm{Ga}\right] \mathrm{Ga}-\mathrm{FAPI}-46$ in the HPLC analysis; $\mathrm{RCP}_{\mathrm{Tot}}=$ Total radiochemical purity; ${ }^{*}$ based on 3 batches; ${ }^{* *}$ based on one batch; ${ }^{* * *}$ based on 2 batches; ${ }^{* * * *}$ Stability was $3 \mathrm{~h}$ EOS for generator-produced and $4 \mathrm{~h}$ for cyclotron-produced.

Table 3. Summary of syntheses and QC of $\left[{ }^{68} \mathrm{Ga}\right] \mathrm{Ga}-\mathrm{DOTATOC}$.

\begin{tabular}{|c|c|c|c|}
\hline Parameter & Product Specification & $\begin{array}{l}\text { Generator-Produced } \\
\left(n=86^{*} \pm \mathrm{SD}\right)\end{array}$ & $\begin{array}{l}\text { Cyclotron-Produced } \\
\quad(n=3 \pm \text { SD })\end{array}$ \\
\hline Start activity (GBq) & Not specified & $1.0 \pm 0.2$ & $9.3 \pm 1.4$ \\
\hline Precursor mass $(\mu \mathrm{g})$ & Not specified & 40 & 40 \\
\hline Product activity (GBq) & Not specified & $0.6 \pm 0.2$ & $6.1 \pm 1.3$ \\
\hline $\begin{array}{l}\text { Activity concentration } \\
(\mathrm{MBq} / \mathrm{mL})\end{array}$ & Not specified & $70.7 \pm 0.2$ & $650 \pm 124$ \\
\hline Non-corrected RCY (\%) & Not specified & $60.9 \pm 7.8$ & $64.4 \pm 4.7$ \\
\hline AMA $(\mathrm{GBq} / \mu \mathrm{mol})$ & Not specified & $21.7 \pm 5.6$ & $215.1 \pm 44.8$ \\
\hline Appearance & $\begin{array}{c}\text { Clear or slightly yellow. Free } \\
\text { of particles }\end{array}$ & Conforms & Conforms \\
\hline $\mathrm{pH}$ & $4.0-8.0$ & $5.8 \pm 0.4$ & $5.5 \pm 0.3$ \\
\hline Product identity & $\left|\mathrm{Rt}_{\mathrm{RD}}-\mathrm{Rt}_{\mathrm{UV}}\right|<120 \mathrm{~s}$ & $83 \pm 7$ & $42 \pm 6$ \\
\hline$\left[{ }^{68} \mathrm{Ga}\right]$ gallium ion on HPLC & $\leq 2 \%$ & Not detected & Not detected \\
\hline $\begin{array}{c}\text { Edotreotide plus }\left[{ }^{68} \mathrm{Ga}\right] \\
{ }^{68} \mathrm{Ga} \text {-DOTATOC }\end{array}$ & $\leq 5 \mu \mathrm{g} / \mathrm{mL}$ & $\leq 5$ & $\leq 5$ \\
\hline Radiochemical impurity, B (\%) & $\leq 3 \%$ & $0.81 \pm 0.61$ & $0.18 \pm 0.16$ \\
\hline $\begin{array}{l}\text { Total radiochemical purity }(\%) \\
\qquad \mathrm{RCP}_{\text {Tot }}=(100-\mathrm{B}) \times \mathrm{T}\end{array}$ & $\geq 91 \%$ & $98.6 \pm 3.6$ & $99.8 \pm 0.2$ \\
\hline Filter integrity (bar) & $\geq 3.5$ bar & $4.0 \pm 0.1^{* *}$ & $4.1 \pm 0.2$ \\
\hline Bacterial endotoxins (EU/mL) & $<1 \overline{7.5} \mathrm{EU} / \mathrm{mL}$ & $<5^{* *}$ & $<5$ \\
\hline Ethanol (\%) & $<10 \%$ & $6.49 \pm 0.32^{* *}$ & $6.4 \pm 0.2$ \\
\hline Sterility & Sterile, 0 CFU & Sterile ${ }^{* *}$ & Sterile \\
\hline Radiochemical stability (\%) *** & $\mathrm{RCP}_{\mathrm{Tot}} \geq 91 \%$ & 97.7 & $99.2 \pm 0.1$ \\
\hline
\end{tabular}

Abbreviations: $\mathrm{RCY}=$ radiochemical yield; $\mathrm{Rt}=$ retention time; $\mathrm{RD}=$ radiodetector; $\mathrm{UV}=$ ultraviolet detector; $\mathrm{B}=$ percentage of radioactivity due to impurity $\left[{ }^{68} \mathrm{Ga}\right.$-ions or -colloids in TLC analysis; $\mathrm{T}=$ proportion of the radioactivity due to $\left[{ }^{68} \mathrm{Ga}\right] \mathrm{Ga}$-DOTATOC in the HPLC analysis; $\mathrm{RCP}_{\text {Tot }}=$ Total radiochemical purity; * Based on clinical batches; ${ }^{* *}$ Based on 10 batches; *** Stability was $3 \mathrm{~h}$ EOS for generator-produced based on one batch while $4 \mathrm{~h}$ EOS for cyclotron-produced. 
Quality control of $\left[{ }^{68} \mathrm{Ga}\right] \mathrm{Ga}-\mathrm{DOTATOC}$ and the product specifications were performed according to Ph. Eur. monograph (PA/PH/Exp. 14/T, monograph number 2482). QC and product specifications of $\left[{ }^{68} \mathrm{Ga}\right] \mathrm{Ga}$-FAPI-46 (EudraCT number 2020-002568-30) were based on the current draft of Ph. Eur. monograph of the ${ }^{68} \mathrm{Ga}$-radiolabeled product. Both were approved by the Medical Product Agency. Following these QC methods, both cyclotronproduced products fulfilled the specification criteria (see Tables 2 and 3). The stability was evaluated up to $4 \mathrm{~h}$ EOS for both tracers, showing a total RCP of over $95 \%$. Both products were stabilized with $4 \mathrm{mg} / \mathrm{mL}$ ascorbate; a longer stability than $4 \mathrm{~h}$ might have been obtained but was not measured.

\section{Discussion}

The feasibility to utilize all high out-put cyclotron-produced ${ }^{68} \mathrm{GaCl}_{3}$ eluate for radiolabeling of DOTA-based tracers is highly dependent on the purity (i.e., content of competing metal ions impurities) of the ${ }^{68} \mathrm{Ga}$-eluate. Impurities may originate from the starting materials, i.e., dilution and wash solutions, tubing, and especially the target material (i.e., the ${ }^{68} \mathrm{Zn}$ foil).

Low content of competing ions such as zinc and iron, especially the trivalent $\mathrm{Fe}^{3+}$, when for example, DOTA is used as a chelator in the radiolabeling, is of great importance. The importance of decreasing the content of $\mathrm{Fe}^{3+}$ in the ${ }^{68} \mathrm{GaCl}_{3}$ eluate is the metal ions' higher stability constant in association with the chelator, i.e., its' ability to form stable complexes with the chelator $[14,15]$.

In this study, we have demonstrated a straight-forward and improved purification approach to achieve a cyclotron solid target produced ${ }^{68} \mathrm{GaCl}_{3}$ eluate with significantly lower levels of competing metal ions (i.e., $\mathrm{Fe}^{3+}$ ) by the addition of ascorbate. Ascorbate is a powerful antioxidant that is commonly used as a radiolytic stabilizer in radiopharmaceuticals $[24,25]$. Here, by utilizing sodium ascorbate's predominant ability to reduce $\mathrm{Fe}^{3+}$ to $\mathrm{Fe}^{2+}$ and its inability to reduce $\mathrm{Ga}^{3+}$ to $\mathrm{Ga}^{2+}$, a more effective separation through the UTEVA resins is possible in the purification process. This enables the use of cyclotron-produced ${ }^{68} \mathrm{GaCl}_{3}$ eluate for high-yield DOTA-chelate complexation with superior results.

AMA values, analyzed by titrations, were 2-, 3- and 16-fold higher for DOTA, NOTA, and HBED, respectively, verifying a considerable improvement. The difference in the AMA increase for the different chelators might possibly be explained by their binding stabilities and stability constants $\left(\log \mathrm{K}_{\mathrm{ML}}\right)$ to $\mathrm{Ga}^{3+}, \mathrm{Fe}^{3+}$ and $\mathrm{Fe}^{2+}$, as further summarized in Table S2, in the Supplementary section. The incredible increase in AMA for HBED may be related to its high $\log \mathrm{K}_{\mathrm{ML}}$ to both $\mathrm{Ga}^{3+}$ and $\mathrm{Fe}^{3+}$. Notably, this purification approach has enabled high-yield DOTA-based radiopharmaceutical productions of $5.58 \pm 0.35 \mathrm{GBq}$ $(n=3)$ for $\left[{ }^{68} \mathrm{Ga}\right] \mathrm{Ga}$-FAPI-46 and $6.1 \pm 1.3 \mathrm{GBq}(n=3)$ for $\left[{ }^{68} \mathrm{Ga}\right] \mathrm{Ga}$-DOTATOC.

High concentrations of competing metal ions may be, alternatively, compensated for by increasing the amounts of precursor used in the radiolabeling, as previously demonstrated [9,11]. For example, Tieu et al. [9] used $80 \mu \mathrm{g}$ of DOTATATE precursor for labeling with $6.3 \mathrm{GBq}{ }^{68} \mathrm{GaCl}_{3}$ and received $3.31 \mathrm{GBq}\left[{ }^{68} \mathrm{Ga}\right] \mathrm{Ga}$-DOTA-TATE (RCY $=70 \%$, $\mathrm{RCP}=68 \%$ ). Thisgaard et al. [11] used $500 \mu \mathrm{g}$ and received $3.22 \mathrm{GBq}\left[{ }^{68} \mathrm{Ga}\right] \mathrm{Ga}$-DOTA-TATE product. This approach will increase the produced radioactivity but will also lower the AMA. This could be problematic due to the restricted maximum peptide dose allowable for patient administration according to the European Pharmacopoeia (e.g., $50 \mu \mathrm{g}$ of DOTATOC [26]). This would consequently limit the shelf life of the radiopharmaceutical product.

Currently, there is no clinical establishment defining the influence of AMA on the imaging utility of ${ }^{68} \mathrm{Ga}$-labeled tracers in oncological applications. It is, however, known from generator-produced batches that clinical imaging is feasible in the AMA ranges of $7-25 \mathrm{GBq} / \mu \mathrm{mol}$. The impact of AMA has been closely investigated in some limited preclinical studies. Lin et al. reported that in vitro cell uptake and better contrast in in vivo preclinical imaging was seen with increasing AMA of [ $\left.{ }^{68} \mathrm{Ga}\right] \mathrm{Ga}-\mathrm{PSMA}-11$ [27]. Increased in vitro cell uptake with AMA was also reported for the same radiotracer by Sanchez-Crespo et al. [28]. In a study by von Hacht et al., the low AMA of the DOTA- 
based ${ }^{68} \mathrm{Ga}$-labeling was resolved by preparative HPLC purification, thereby improving the detection of small metastases [29]. The level of AMA and its impact in diagnostics is an interesting and important aspect, which is made available also for DOTA-based ${ }^{68} \mathrm{Ga}$-labeled radiopharmaceuticals by the results from this present study.

It is of considerable interest to be able to utilize cyclotron-produced ${ }^{68} \mathrm{Ga}$ eluate in kit preparations of ${ }^{68} \mathrm{Ga}$-based tracers, as more kits are elegantly prepared for one single vial compounding in which the eluate is directly added, thereby minimizing radiation exposure and handling. The high AMA cyclotron-produced ${ }^{68} \mathrm{Ga}$ eluate obtained here warrants/can facilitate future kit preparation procedures.

\section{Conclusions}

In this study, we have demonstrated a purification approach to decrease the levels of competing metal ions (i.e., $\mathrm{Fe}^{3+}$ ) in cyclotron-produced ${ }^{68} \mathrm{GaCl}_{3}$ eluate and enabled GMP-compliant high-yield DOTA-peptide synthesis of clinically relevant tracers. The ${ }^{68} \mathrm{GaCl}_{3}$ eluate from the solid-target production may be used in its full volume for further DOTA-based ${ }^{68} \mathrm{Ga}$-labeling without compromising the radiochemical yields or the need of increasing the amounts of precursor. Titrations indicate that radiolabeling of NOTA- or HBED-based tracers may give even better yields. To our knowledge, the apparent molar activity, AMA in the range of 100 and $200 \mathrm{GBq} / \mu \mathrm{mol}$ obtained from the syntheses of the DOTA-based tracers, is so far the highest achieved using cyclotron-produced ${ }^{68} \mathrm{GaCl}_{3}$ eluate based on our purification method.

Supplementary Materials: The following are available online at https: / www.mdpi.com/article / 10.3390/biom11081118/s1, Figure S1: Representative HPLC chromatograms for the quality control of [ $\left.{ }^{68} \mathrm{Ga}\right] \mathrm{Ga}-F A P I-46$ where A. UV detection at $264 \mathrm{~nm}$ of the reference sample of Ga-FAPI-46 and B. Radiochromatogram of $\left[{ }^{68} \mathrm{Ga}\right] \mathrm{Ga}-\mathrm{FAPI}-46$, Figure S2: Representative HPLC chromatograms for the quality control of $\left[{ }^{68} \mathrm{Ga}\right] \mathrm{Ga}$-DOTATOC, where A. UV detection at $220 \mathrm{~nm}$ of the reference sample of edotreotide and B. Radiochromatogram of $\left[{ }^{68} \mathrm{Ga}\right] \mathrm{Ga}$-DOTATOC sample, Table S1: ICP-MS analysis of cyclotron-produced ${ }^{68} \mathrm{GaCl}_{3}$ eluate, Table S2: Comparison of the log stability constants, $\log \mathrm{K}_{\mathrm{ML}}$ for the different chelators.

Author Contributions: Conceptualization, E.J., S.M., J.S. and T.A.T.; methodology, E.J., S.M., J.S., M.M.M. and T.A.T.; validation, E.J., S.M., J.S., M.M.M., L.B. and T.A.T.; formal analysis, E.J., S.M., J.S. and T.A.T.; investigation, E.J., S.M., J.S. and T.A.T.; resources, T.A.T., E.S.; data curation E.J., S.M., T.A.T.; writing—original draft preparation, E.J., T.A.T.; writing-review and editing, all authors; supervision, T.A.T.; project administration T.A.T.; funding acquisition, T.A.T., R.A., E.S. All authors have read and agreed to the published version of the manuscript.

Funding: This research was partly funded by the Swedish Cancer Society.

Institutional Review Board Statement: Not applicable.

Informed Consent Statement: Not applicable.

Data Availability Statement: The data presented in this study are available on request to the corresponding authors.

Acknowledgments: The staff at Karolinska Radiopharmacy are acknowledged for their contribution to the clinical productions of $\left[{ }^{68} \mathrm{Ga}\right] \mathrm{Ga}-\mathrm{DOTATOC}$. Sofie Biosciences for providing the FAPI-46 precursor for this study. The Cancer Research Funds of Radiumhemmet and the King Gustaf V Jubilee Fund for providing EJ research time. Sharon Stone-Elander for input and language editing.

Conflicts of Interest: The authors declare no conflict of interest.

\section{References}

1. Martiniova, L.; Palatis, L.; Etchebehere, E.; Ravizzini, G. Gallium-68 in Medical Imaging. Curr. Radiopharm. 2016, 9, $187-207$. [CrossRef] [PubMed]

2. Roesch, F.; Riss, P.J. The renaissance of the (6)(8)Ge/(6)(8)Ga radionuclide generator initiates new developments in (6)(8)Ga radiopharmaceutical chemistry. Curr. Top. Med. Chem. 2010, 10, 1633-1668. [CrossRef] [PubMed] 
3. Velikyan, I. 68Ga-Based radiopharmaceuticals: Production and application relationship. Molecules 2015, 20 , 12913-12943. [CrossRef] [PubMed]

4. Kumar, K. The Current Status of the Production and Supply of Gallium-68. Cancer Biother Radiopharm. 2020, 35, 163-166. [CrossRef] [PubMed]

5. AuntMinnie.com. FDA Clears Cyclotron Ga-68 DOTATOC Production Process. Available online: https://www.auntminnie.com/ index.aspx?sec=ser\&sub=def\&pag=dis\&ItemID=130589 (accessed on 21 June 2021).

6. Pandey, M.K.; Byrne, J.F.; Jiang, H.; Packard, A.B.; DeGrado, T.R. Cyclotron production of (68)Ga via the (68)Zn(p,n)(68)Ga reaction in aqueous solution. Am. J. Nucl. Med. Mol. Imaging 2014, 4, 303-310.

7. Rodnick, M.E.; Sollert, C.; Stark, D.; Clark, M.; Katsifis, A.; Hockley, B.G.; Parr, D.C.; Frigell, J.; Henderson, B.D.; Abghari-Gerst, M.; et al. Cyclotron-based production of (68)Ga, [(68)Ga]GaCl3, and [(68)Ga]Ga-PSMA-11 from a liquid target. EJNMMI Radiopharm. Chem. 2020, 5, 25. [CrossRef]

8. Lin, M.; Waligorski, G.J.; Lepera, C.G. Production of curie quantities of (68)Ga with a medical cyclotron via the (68)Zn(p,n)(68)Ga reaction. Appl. Radiat. Isot. 2018, 133, 1-3. [CrossRef]

9. Tieu, W.; Hollis, C.A.; Kuan, K.K.W.; Takhar, P.; Stuckings, M.; Spooner, N.; Malinconico, M. Rapid and automated production of [(68)Ga]gallium chloride and [(68)Ga]Ga-DOTA-TATE on a medical cyclotron. Nucl. Med. Biol. 2019, 74-75, 12-18. [CrossRef] [PubMed]

10. Nelson, B.J.B.; Wilson, J.; Richter, S.; Duke, M.J.M.; Wuest, M.; Wuest, F. Taking cyclotron (68)Ga production to the next level: Expeditious solid target production of (68)Ga for preparation of radiotracers. Nucl. Med. Biol. 2020, 80-81, 24-31. [CrossRef] [PubMed]

11. Thisgaard, H.; Kumlin, J.; Langkjaer, N.; Chua, J.; Hook, B.; Jensen, M.; Kassaian, A.; Zeisler, S.; Borjian, S.; Cross, M.; et al. Multi-curie production of gallium-68 on a biomedical cyclotron and automated radiolabelling of PSMA-11 and DOTATATE. EJNMMI Radiopharm. Chem. 2021, 6, 1. [CrossRef] [PubMed]

12. Becker, K.V.; Chernysheva, M.; Barnhart, T.E.; Gagnon, K.; Engle, J.W. A review of accelerator-produced Ga-68 with solid targets. Curr. Radiopharm. 2020. [CrossRef] [PubMed]

13. Siikanen, J.; Jussing, E.; Milton, S.; Steiger, C.; Ulin, J.; Jonsson, C.; Samén, E.; Tran, T.A. Cyclotron-produced 68Ga from enriched 68Zn foils. Appl. Radiat. Isot. 2021, 109825. [CrossRef] [PubMed]

14. Martell, A.E.; Motekaitis, R.J.; Chen, D.; Hancock, R.D.; McManus, D. Selection of new Fe(III)/Fe(II) chelating agents as catalysts for the oxidation of hydrogen sulfide to sulfur by air. Can. J. Chem. 1996, 74, 1872-1879. [CrossRef]

15. Martell, A.E.; Motekaitis, R.J.; Clarke, E.T.; Delgado, R.; Sun, Y.; Ma, R. Stability constants of metal complexes of macrocyclic ligands with pendant donor groups. Supramol. Chem. 1996, 6, 353-363. [CrossRef]

16. EDQM Council of Europe. European Pharmacopoeia. Gallium $(68 \mathrm{Ga})$ chloride (accelerator-produced) solution for radiolabelling Monograph PA/PH/Exp. 14/T (18) 13 ANP: 3109; EDQM Council of Europe: Strasbourg, France, 2020.

17. Marinov, G.M.; Marinova, A.P.; Medvedev, D.V.; Dadakhanov, J.A.; Milanova, M.M.; Happel, S.; Radchenko, V.I.; Filosofov, D.V. Determination of distribution coefficients $(\mathrm{Kd})$ of various radionuclides on UTEVA resin. Radiochim. Acta 2016, 104, 735-742. [CrossRef]

18. McAlister, D.R.; Philip Horwitz, E. Automated two column generator systems for medical radionuclides. Appl. Radiat. Isot. 2009, 67, 1985-1991. [CrossRef] [PubMed]

19. Lee, M.-S.; Lee, K.-J.; Oh, Y.-J. Solvent Extraction Equilibria of $\mathrm{FeCl}_{3}$ from Hydrochloric Acid Solution with Alamine336. Mater. Trans. 2004, 45, 2364-2368. [CrossRef]

20. Ilbert, M.; Bonnefoy, V. Insight into the evolution of the iron oxidation pathways. Biochim. Biophys. Acta (BBA) Bioenerg. 2013, 1827, 161-175. [CrossRef] [PubMed]

21. Chung, Y.; Lee, C.-W. Electrochemistry of Gallium. J. Electrochem. Sci. Technol. 2013, 4, 1-18. [CrossRef]

22. Borsook, H.; Keighley, G. Oxidation-Reduction Potential of Ascorbic Acid (Vitamin C). Proc. Natl. Acad. Sci. USA 1933, 19, 875-878. [CrossRef]

23. IAEA-TECDOC-1863. Gallium-68 Cyclotron Production; International Atomic Energy Agency: Vienna, Austria, 2019.

24. Liu, S.; Ellars, C.E.; Edwards, D.S. Ascorbic acid: Useful as a buffer agent and radiolytic stabilizer for metalloradiopharmaceuticals. Bioconjug. Chem. 2003, 14, 1052-1056. [CrossRef] [PubMed]

25. Fukumura, T.; Nakao, R.; Yamaguchi, M.; Suzuki, K. Stability of 11C-labeled PET radiopharmaceuticals. Appl. Radiat. Isot. 2004, 61, 1279-1287. [CrossRef] [PubMed]

26. EDQM Council of Europe. European Pharmacopoeia. Gallium (68Ga) Edotreotide Injection PA/PH/Exp. 14/T (07) 12 COM ANP: 2482; EDQM Council of Europe: Strasbourg, France, 2011.

27. Lin, M.; Paolillo, V.; Ta, R.T.; Damasco, J.; Rojo, R.D.; Carl, J.C.; Melancon, M.P.; Ravizzini, G.C.; Le, D.B.; Santos, E.B. Fully automated preparation of (68)Ga-PSMA-11atcurie level quantity using cyclotron-produced (68)Ga for clinical applications. Appl. Radiat. Isot. 2020, 155, 108936. [CrossRef] [PubMed]

28. Sanchez-Crespo, A.; Jussing, E.; Bjorklund, A.C.; Pokrovskaja Tamm, K. Hallmarks in prostate cancer imaging with Ga68-PSMA11-PET/CT with reference to detection limits and quantitative properties. EJNMMI Res. 2018, 8, 27. [CrossRef]

29. Von Hacht, J.L.; Erdmann, S.; Niederstadt, L.; Prasad, S.; Wagener, A.; Exner, S.; Beindorff, N.; Brenner, W.; Grotzinger, C. Increasing molar activity by HPLC purification improves 68Ga-DOTA-NAPamide tumor accumulation in a B16/F1 melanoma xenograft model. PLoS ONE 2019, 14, e0217883. [CrossRef] 